\title{
Students' Perceived Quality of Distance Education Courses as a Correlate of Learner Satisfaction: A Case Study of the Bachelor of Education Arts Program, University of Nairobi, Kenya.
}

\author{
Joyce Kanini Mbwesa \\ Correspondence: Joyce Kanini Mbwesa, School of Continuing and Distance Education, Department of Educational \\ Studies, University of Nairobi, Kenya.
}

Received: January 13, 2014 Accepted: January 29, 2013 Available online: February 25, 2014

doi:10.11114/ijsss.v2i2.358

URL: http://dx.doi.org/10.11114/ijsss.v2i2.358

\begin{abstract}
Distance education (DE) has in the past few decades evolved into a complex and dynamic instructional approach that is feeding discussions that range from the quality of learning supported by this mode of delivery to the efficacy of the approach. One of the key discussions that has attracted interest and research in this approach of instructional delivery is the construct of quality and quality assurance in Distance education courses. Quality in distance education has largely and often been studied from national and institutional administrative and faculty stand points. Very few studies have analyzed quality in DE from the learners' perspectives. This study analyzed the construct of quality as perceived by the distance learner and the influence of this perception on the students' satisfaction with the DE course. In Particular, the analysis focused on identifying students perceptions of key variables that define the construct of quality from their perspective. A questionnaire, Students Perceived quality in DE questionnaire (SPQQ) constructed by the researcher was used as the key tool of data collection. Descriptive and correlational statistics were the main tools of analysis used. Results of the study clearly indicated that the theory predictor variables (SPQP, SPQI, SPQC, and SPQE ) were all positively correlated with perceived students satisfaction with the DE course. Learners particularly seemed to value fair and clear learning assessment guidelines and periodic students' evaluation of teaching and learning. The study points to the conclusion that institutions must pay attention to factors such as quality of pedagogy, learner support, technological and even physical infrastructure structure as a measure of meeting students' quality expectations.
\end{abstract}

Keyword: Students' perceived quality, perceived students' satisfaction, quality of pedagogy, learner support, technological infrastructure

\section{Introduction}

Distance education (DE) has in the past few decades evolved into a complex and dynamic instructional approach that is feeding discussions that range from the quality of learning supported by this mode of delivery to the efficacy of the approach to what influences how learning happens in this entity. One of the key discussions that have attracted interest and research in this approach of instructional delivery is the construct of quality and quality assurance in Distance education courses. As a concept, the construct of Quality is relative and evolving. In higher education, quality is a construct relative to the unique perspectives and interpretations of different stakeholder groups - students, alumni, faculty, administrators, parents, oversight boards, employers, state legislatures, local governing bodies, accrediting associations, transfer institutions, and the general public.

Quality assurance has been defined as "systematic management and assessment procedures adopted by higher education institutions and systems in order to monitor performance against objectives, and to ensure achievement of quality outputs and quality improvements" (Harman 2000). Harman further argues that Quality assurance facilitates recognition of the standards of awards, serves public accountability purposes, helps inform student's choice, contributes to improved teaching learning and administrative processes, and helps disseminate best practices with the goal of leading to overall improvement of higher education systems. However, Harman cautions that setting common standards and evaluation criteria, must take into account diversity and plurality of higher education within national, as well as regional systems. Assuring the quality of education provision is a fundamental aspect of gaining and maintaining credibility for programs, institutions and national systems of higher education worldwide.

Over the past few years, quality assurance in distance and higher education has gained serious attention by institutions, stakeholders, and scholars. In response to QA demands from stakeholders, institutions of higher learning have begun to re-define and re-orient their institutional missions and strategic visions to incorporate and address quality issues. With 
the proliferation of Distance learning programs and online learning providers and the challenges presented by the distance education sector in general to state regulators and accrediting bodies, it is paramount to address issues of the efficacy of quality assurance in DE.

There has been significant growth of quality assurance (QA) activities aimed towards improving higher education on institutional, national, regional, and global levels. Public and institutional stakeholders seeking accountability in higher education have encouraged governments to establish national quality assurance and accreditation agencies. Many Agencies, such as United Nations Educational, Scientific and Cultural Organization (UNESCO), commission for higher education Kenya, European Network of Quality Assurance (ENQA) among others typically works together and share information about quality standards, benchmarks and best practices.

Quality in distance education has largely and often been studied from national and institutional administrative and faculty stand points. Frydenberg (2002), notes that while inputs from providers, assessors, and governments are valuable in managing and enhancing quality in DE, students perspectives and viewpoints must also be considered. After all, the success of DE does not derive just from the products and services delivered to the learner but also from the knowledge, understanding, and relationships that are co-developed by both learners and teachers during the teaching and learning processes (Ehlers, 2004; Jung, 2011; Tucker, 2010). Very important is to acknowledge the fact that improving learning experiences, performance, and learners' satisfaction with the DE course is dependent highly on understanding their perceptions of quality DE among other factors.

Over the last few decades, Africa and Kenya in Particular have witnessed a proliferation of Distance learning programs and online learning providers. The University of Nairobi for example offers many educational programs by use of Distance education methodologies. Since 1986, the University of Nairobi has provided DE courses through the School of Continuing and Distance education (SCDE), department of educational studies. This is when the first group of 600 students was admitted to the Bachelor of Education (Arts) course (University of Nairobi, 1990). A relatively new program of Bachelor of Education (Science) was also launched in 2003. Print has been the main media that has largely been utilized. This involves sending out study modules to the learners who are spread over wide geographical areas. Occasional residential sessions that involve face to face teaching and interactions with the learners are also organized. These face to face interactions are limited to about two weeks in which learners have opportunities for face to face tutorials, practical assignments, examination among other key activities.

However, the notable growth in use of DE methodologies has not been without many challenges ranging from effectiveness of learning to quality of the programs offered through DE methodologies. And whereas Quality in distance education has largely and often been studied from national and institutional administrative and faculty stand points very few studies have analysed quality in DE from the learners' perspectives (Frydenberg, 2002, Jung, I. S, 2011). Parker 2004 notes that the greatest challenge in trying to define quality in any product or service is that quality remains a relative experience, realized in large part through an individual's level of expectation... 'since quality necessarily rests in the eye of the beholder' (Parker 2004 pg.6). This clearly implies that it is important to understand the construct of quality through the eyes of the distance learner. After all, the inherent nature of distance education places additional responsibilities on students and therefore quality should and must be seen in the students' lenses. This therefore was the situate of the present analysis. The study was an attempt to analyse the construct of quality as perceived by (the Delete) distance learners enrolled for a Bachelor of Education (Arts) program at the University of Nairobi and the influence of this perception on the students' satisfaction with the DE course. In Particular, the analysis focused on identifying students' perceptions of key values and variables that define the construct of quality from their perspective.

\subsection{Review of Related Literature}

Quality in DE has been viewed from different perspectives. Bulewati, \& Zuhairi (2007) examined the experiences of Universitas Terbuka (UT) in implementing a quality management system and concluded that quality assurance must be developed as an institutional policy and strategy for continuous improvement.

Nugraheni et al (2013) studied students' perception on quality assurance (QA) system of distance education, using an online survey method involving 306 students at Universitas Terbuka (UT). They analysed students' perception on QA system in terms of profile of respondents, perception on important values of QA, students' satisfaction on the quality of the distance education programs and courses. Their study revealed that Distance learning students (DLS) students needed both academic and social psychological support and that external accreditation and qualified staff are key factors to institutional quality. Students also seemed to value the importance of well-structured courses and interactivity in the learning process. Other key findings that were reported from this study are that media technology supports, faculty support, and fair assessment are important in the quality of teaching learning at a distance and that protection of student rights, course content, and technology infrastructure were well facilitated by the institution.

Daugherty and Barbara (1998) examined perspectives of university faculty and students currently involved web-based instruction. Their results indicated that Students and faculty benefitted from meaningful learning of technology through 
the integration of course content and computer applications, increased access to the most current and global content information available, increased motivation, and convenience. Faculty reported a wide range of challenges in the development and delivery of Web-based instruction. The most frequently identified barriers included lack of technical support, lack of software/adequate equipment, lack of faculty/administrative support, the amount of preparation time required to create assignments, and student resistance. Faculty respondents in this study consistently identified convenience and improved learning as advantages for students enrolled in Web-based instruction.

Cashion and Palmieri (2002) investigated Australian learners' and educators' views on the quality of online learning. Flexibility, in utilizing e-learning technology was rated as the most important factor in quality e-learning by learners. Other quality factors cited as highly important by most educators, such as induction, communication with teachers and other students, and a hybrid mix of face-to-face and online learning, were rated as less important by the learners. Strangely, in this study, learners did not indicate any need for a lot of induction, initial support, or technology training to study online, while educators believed that they would demand far more support. Jung (2011) found that South Korea's e-learners perceived staff support to be the most important indicator of e-learning quality, followed by institutional QA mechanisms and learning tasks.

The present study was therefore an attempt to analyse the construct of quality as perceived by the distance learner and the influence of this perception on the students' satisfaction with the DE course.

\subsection{Conceptual Model}

The conceptual model adopted in this study was highly influenced by the ideas of Jung 2011 who studied Asian learners' perceptions about the quality of DE and examined gender differences in such perceptions. Basing her ideas from Asian countries' QA systems for DE, Jung developed 10 categories model that defined different dimensions of quality as perceived by the distance learner. These dimensions are summarised below:

1) The faculty support dimension deals with policies and procedures for training, support during course development and delivery, and faculty welfare.

2) The student support dimension deals with policy and guidelines for technical, financial, psychological, social, and administrative support, flexible payment, and appeal.

3) The information \& publicity dimension refers to the provision of course-related and other logistical information and clear indication of requirements.

4) The interactive tasks dimension refers to learning activities that promote learner inter -actions in various forms of distance learning.

5) The institutional quality assurance mechanism dimension refers to policy measures and activities by a DE institution with regard to the existence of QA standards and guidelines specifically for DE, and periodic internal and external evaluations.

6) The institutional credibility dimension refers to the status of acquiring both national and international accreditations, showing strong leadership, and guaranteeing member qualifications that promote a DE institution's public credibility.

7) The course development dimension refers to policies and guidelines that help ensure and maintain the quality of course development processes, materials, and resources, and the course content's adaptability to learners.

8) The teaching and learning dimension refers to activities related to pedagogy in DE as well as online and physical resource provision.

9) The evaluation and assessment dimension refers to activities and policies concerned with students' learning assessment and feedback as well as various stakeholders' evaluations.

10) The infrastructure dimension refers to the policies and measures that ensure the reliability and security of technology systems as well as the provision of physical spaces.

Based on this model and for the purposes of this study, a six dimension model defining the various dimensions of quality in DE was constructed. These six quality dimensions were found to be most relevant in the context of the study because whereas Jung's context was large involving several Asian countries, the present analysis was a small case study looking at the students' perceived quality of DE in one single program, Bachelor of education arts of the university of Nairobi. Therefore the six dimensions that defined the foundation of the present analysis included, Pedagogical domain, Leaner support domain, institutional credibility domain, Infrastructure domain, Faculty domain and Evaluation domains.

Pedagogical domain related to DE content, course design, multi media used, and course evaluation. Leaner support related to variables such as learner welfare, administrative support, psychosocial student support. The institutional credibility domain refers to the status of acquiring both national and international accreditations, showing strong leadership, and guaranteeing member qualifications that promote a DE institution's public credibility. Infrastructure domain refers to physical infrastructure and technological infrastructure such as availability of computer labs, internet 
access, library among other facilities. Faculty domain deals with policies and procedures for training, support during course development and delivery, and faculty welfare. Evaluation and assessment domain refers to activities and policies concerned with students' learning assessment and feedback as well as various stakeholders' evaluations Evaluation.

These dimensions therefore formed the basis of the conceptual framework adopted in this study. Figure one depicts this model.

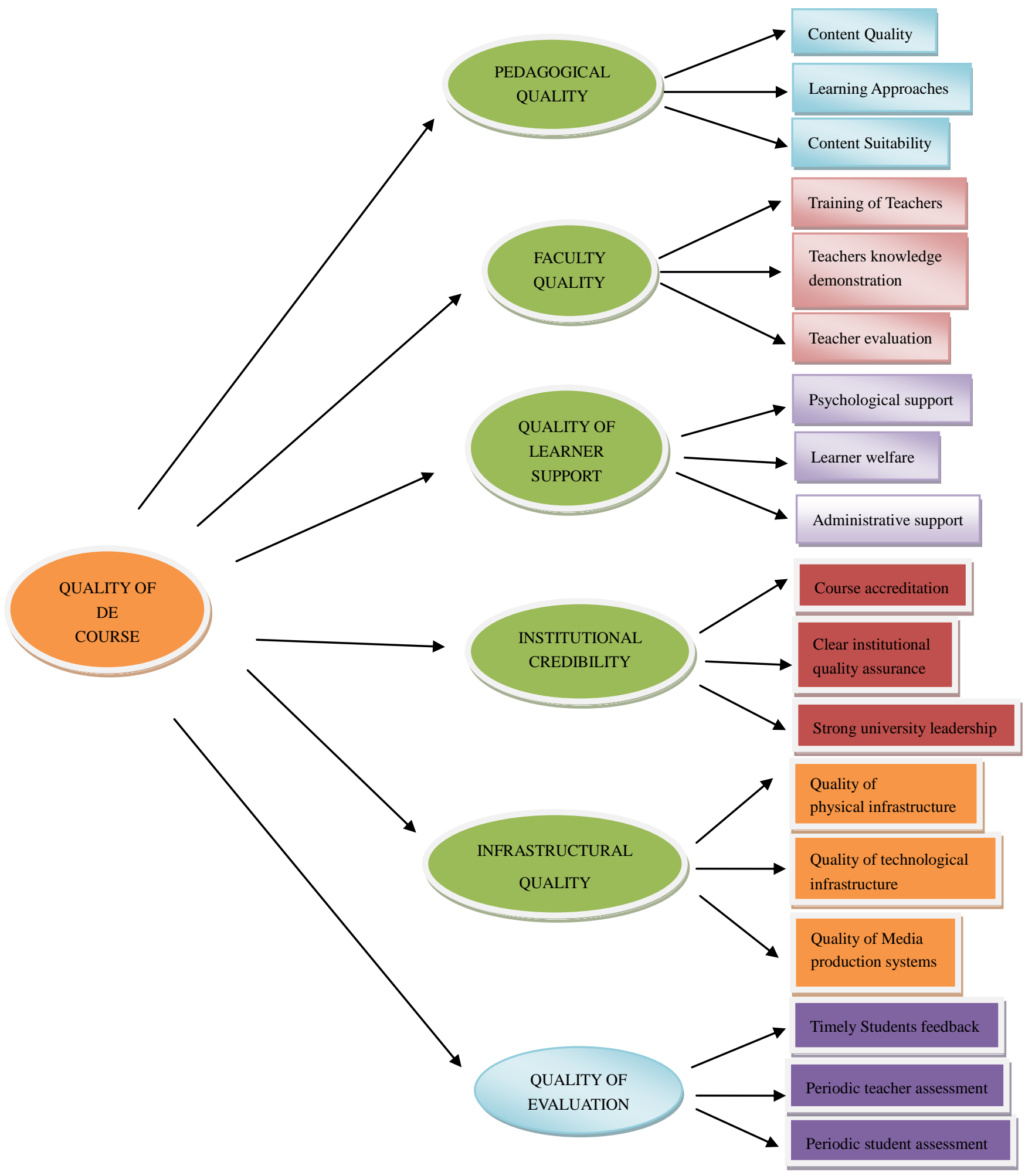

Figure 1. Conceptual Model 


\subsection{Purpose of the Study}

The Purpose of the study was to analyse the construct of quality as perceived by distance learners enrolled for a Bachelor of Education (Arts) program at the University of Nairobi and the influence of this perception on the students' satisfaction with the DE course. In Particular, the analysis focused on identifying students' perceptions of different dimensions that define the construct of quality in DE from their perspective and how this influences students' satisfaction with the DE course.

\subsection{Objectives of the Study}

Specifically, the following were the objectives of the study:

1) Analyse students' perception of the quality of pedagogy (SPQP) in the DE course and its influence on students' perceived satisfaction (SPS) with DE course.

2) Establish students' perception of the quality of Learner support (SPQL) in the DE course and its influence on students' perceived satisfaction (SPS) with the course.

3) Identify students' perception of the quality of Faculty (SPQF) and its influence on students' perceived satisfaction (SPS) with the DE course.

4) Analyse students' perception of the quality of infrastructure and its influence on students' perceived satisfaction (SPS) with the DE course.

5) Establish students' perceived institutional creditability and its influence on students' perceived satisfaction (SPS) with the DE course.

6) Analyse students' perceived quality of institutional evaluation mechanisms and how this influences students' perceived satisfaction (SPS) with the DE course.

\subsection{Research Questions}

The analysis was guided by the following research questions:

1) To what extent does students' perception of the quality of pedagogy (SPQP) in the DE course influence students' perceived satisfaction (SPS) with DE course?

2) Is there a relationship between students' perception of the quality of Learner support (SPQL) in the DE course and students' perceived satisfaction (SPS) with the course?

3) To what extent does students' learners' perception of the quality of Faculty (SPQF) influence students' perceived satisfaction (SPS) with the DE course?

4) Is there a significant relationship between students' perception of the quality of infrastructure and students' perceived satisfaction (SPS) with the DE course?

5) Does students' perception on institutional creditability influence students' perceived satisfaction (SPS) with the DE course?

6) Does students' perceived quality of institutional evaluation mechanisms influence students' perceived satisfaction (SPS) with the DE course?

\section{Research Design and Methodology}

Survey analysis was the main research design adopted in this study. Data was collected from a random sample of 248 students Pursuing a Bachelor of Education (arts) program through distance learning at the university of Nairobi Kenya.

\subsection{Instruments}

A questionnaire, Students Perceived quality in DE questionnaire (SPQQ) constructed by the researcher was used as the key tool of data collection. The questionnaire was structured with two key sections. Section A sought information about personal students characteristics or profile which was considered as key in this analysis. Section B of the questionnaire constituted of closed-ended Likert five point question items (ranging from 1 (strongly disagree) to 5 (strongly agree). These measured different dimensions of students perceived Quality (SPQ) of DE courses.

In developing this questionnaire, an initial list of quality dimensions for use in the study were identified through literature review (Jung 2011 ) and six categories defining the various dimensions of quality in DE were created. These six dimensions defined the foundation of analysis for this study and include the following:

1) Pedagogical domain related to DE content, course design and multi media used. 
2) Leaner support related to variables such as learner welfare, administrative support and psychosocial student support among other variables.

3) The institutional credibility dimension refers to the status of acquiring both national and international accreditations, showing strong leadership, and guaranteeing member qualifications that promote a DE institution's public credibility.

4) Infrastructure dimension related to physical and technological infrastructure such as availability of computer labs, internet access, and library services among other facilities.

5) Faculty dimension deals with policies and procedures for training support during course development and delivery, and faculty welfare.

6) The evaluation and assessment dimension was used in this study to refer to activities and policies concerned with students' learning assessment and feedback.

\subsection{Reliability Testing}

Reliability testing for internal consistency of the Likert research items was performed through a calculation of Cronbach's Alpha coefficients whose formula is as indicated below and whose values are summarized in Table 1.

$$
\alpha=\frac{K}{K-1}\left(1-\frac{\sum_{i=1}^{K} \sigma_{Y_{i}}^{2}}{\sigma_{X}^{2}}\right)
$$

Where $\sigma_{X}^{2}$ is the Variance of the observed total test scores, and $\sigma_{Y_{i}}^{2}$ is the variance of component $i$ for the current sample. $K$ is the number of items considered.

All of the coefficients of the sub-scales were above 0.7 which are acceptable (Cortina 1993, Revelle, 1979, Nunnally, 1978) except SPQE whose coefficient was 0.612 but which is still acceptable in the behavioral sciences . See Table 1.

Table 1. Cronbach's Alpha Coefficient

\begin{tabular}{lc}
\hline Grouped Variables & Coefficient \\
\hline students perception of the quality of pedagogy (SPQP) & .825 \\
students perception of the quality of Learner support (SPQL & .733 \\
students learners' perception of the quality of faculty (SPQF) & .732 \\
students perception on the quality of infrastructure (SPQI) & .887 \\
students' perceived institutional creditability (SPQC) & .936 \\
Students perceived quality of institutional evaluation (SPQE) & .612. \\
students' perceived satisfaction (SPS) with the DE course & .824 \\
\hline
\end{tabular}

\subsection{Data Analysis}

Descriptive and correlational statistics were the main tools of analysis used. Grouping of categories to satisfy test prerequisite conditions were done. For example, all Likert scale items measuring different dimensions of learners' perception of the quality of the DE course were grouped to constitute specific component constructs renamed after the regrouping process. For example, the ten items measuring students' perception of the quality of teaching and learning were regrouped into one single construct variable renamed students' perception of the quality of pedagogy (SPQP). The same was done for all other measurement items. The use of combined groups of variables as representatives of the underlying "components" rather than using the individual variables themselves was found to be more useful and meaningful. This process is based on the assumption that the underlying components cannot be measured directly but that they influence in an organized way the values of the variables that can be measured.

Spearman's rho correlation coefficients were calculated for all identified predictor Components of students learners' perception of the quality of the DE course paired with the response variable - Student perceived satisfaction with DE course (SPS). Spearman's rho coefficient was used instead of the Pearson coefficient because most variables were of ordinal nature. Contingency tables were created and regrouped when necessary, and the test calculations performed using SPSS.

\section{Results and Discussions}

Before the computation of correlations of the key domain variables that assessed the influence of the predictor variables (Student perceived quality of pedagogy in DE course (SPQP) on the response variable (Student perceived satisfaction), 
descriptive statistics was used to explore the data for the distribution of the responses on the Likert scale items. And although the data provided by these variables does not contribute directly to answering the key research questions, it was intended to explore the data for description purposes.

\subsection{Respondents Demographic Profile}

Table 2. Demographic profile of the respondents

\begin{tabular}{llll}
\hline Item & Scale & Frequency & Valid percentage \\
\hline Gender & Male & 106 & 42.7 \\
\multirow{3}{*}{ Marital status } & Female & 142 & 57.3 \\
& Married & 197 & 79.4 \\
Age & Single & 51 & 20.6 \\
& Below 25 & 26 & 10.5 \\
Career & $25-39$ & 151 & 61.8 \\
& $40-54$ & 71 & 28.6 \\
Work experience & 231 & 93.1 \\
& Teachers & 17 & 6.9 \\
& Administrators & 64 & 25.8 \\
& 6- 10 years & 90 & 36.3 \\
& 11- 15 years & 48 & 19.4 \\
& Over 15 years & 46 & 18.5 \\
\hline
\end{tabular}

A total of 248 students participated in the study. Demographic analysis of the data revealed that that there were more female $(57.3 \%)$ in the program than male who constituted $42.7 \%$. The respondents age ranged between below 25 years 54 years with majority $(61.8 \%)$ falling in the bracket of $25-39$ years. It is interesting to note that a sizeable number of the students $(28.6 \%)$ are quite mature students falling in the age bracket of $40-54$ years. This is a group nearing retirement and the result indicates that the program is quite inclusive in the sense that it does serve the needs of the mature student who still wish to further their studies. The analysis also indicated that many (79.4\%) of the students are actually married with majority (77.4\%) having between 1-4 children. Only a few (20.6\%) indicated that they were single. Majority of the students $(88.7 \%)$ also hold prior primary school teacher education training certificate (PI) and only very few $(8.9 \%)$ are fresh students with high school certificate. These implies that the program serves largely practicing teachers who are pursuing a further education to upgrade their professional training.

Many of the students are also on full time employment (74.2\%) and perhaps these could explain their choice of Distance education as the suitable learning approach. Distance education of course does provide the flexibility to the students which is not just available in conventional systems of education. In fact, almost all are practising teachers (93.1\%) with majority (55.7\%) having a work experience of 6- 15 years. This implies that most of the students are in indeed in the middle life of their careers where they still have to build strong foundation for their career growth. Only a few $(6.9 \%)$ of the students are in other career paths. It is also interesting to note that although many of the students (77.4\%) serve as regular teachers, a few are in managerial positions such as school head teachers and departmental heads $(12.9 \%)$. See table 2

\subsection{Perception on the Quality of Pedagogy (SPQP)}

One of the objectives of this study was to analyse students' perception of the quality of pedagogy (SPQP) in the DE course and its influence on students' perceived satisfaction (SPS) with the course. Pedagogy was identified as one of the domains that define the quality of a distance learning program. This domain has also been used for defining quality in DE in other studies (Jung 2011). In this analysis, pedagogy was operationally defined as Pedagogical effectiveness in the learning and teaching process. This domain was defined by $10 \mathrm{key}$ related variables and measured though closed-ended Likert five point question items (ranging from 1 (strongly disagree) to 5 (strongly agree). Initially the items measuring this variable were 12. However, after performing a Reliability testing for internal consistency of the items, two items that scored below the threshold of $\alpha=0.7$ were found not suitable and therefore were eliminated from the final scale that was adopted. The 10 measures for the pedagogical domain are summarised in table 3 below which also summarises the standard deviation and mean distributions. 
Table 3. Standard deviation and mean distributions of SPQP

\begin{tabular}{llll}
\hline Variable name & Item measure on a Likert scale & ME & SD \\
\hline VP1 & The content of this course is of high quality & 2.5388 & 0.64934 \\
VP2 & Course content is well constructed & 2.4735 & 0.69269 \\
VP3 & Student teacher interaction is effective & 2.3837 & 0.67123 \\
VP4 & There is flexibility in the learning approaches and methods & 2.5429 & 0.64909 \\
VP5 & Face to face tutorial are very effective & 2.5102 & 0.68120 \\
VP6 & There is flexibility in learning pace & 2.5592 & 0.75311 \\
VP7 & There is inclusion of collaborative learning activities in our course & 2.5673 & 0.95415 \\
VP8 & Inclusion of individual learning activities in the course & 2.6898 & 0.55966 \\
VP9 & The course content is quite adaptable to my needs & 2.7143 & 0.57260 \\
VP10 & The course suites my level of understanding & 2.7959 & 0.51133 \\
\hline
\end{tabular}

All variables measuring SPQP were scored highly with mean scores ranging between $\mathrm{M}=2.3837, \mathrm{SD}=0.69269$ and $\mathrm{M}$ $=2.7959, \mathrm{SD}=0.51130$. For example, majority of the students considered content to be of high quality $(\mathrm{ME}=2.5388$, $\mathrm{SD}=0.6934)$. Other variables that scored highly in this analysis include Course suitability with learners level of understanding $(\mathrm{ME}=2.7143, \mathrm{SD}=0.5113)$, course adaptability to students needs $(\mathrm{ME}=2.7143, \mathrm{SD} 0.5726)$, collaborative learning $(\mathrm{ME}=2.5673, \mathrm{SD}=0.95415)$ and flexibility in learning pace $(\mathrm{ME}=2.5592, \mathrm{SD}=0.75311)$. However, the item on quality of students teacher interaction (ME 2.3837, $\mathrm{SD}=0.67123$ ) and quality on course structure $(\mathrm{ME}=2.4727, \mathrm{SD}=0.69269)$ scored below the average mean score. This implies that majority of the students perceive student teacher interaction and course structure as being of law quality. This result is consisted with other studies that have reported transactional distance between students and teachers (Moore, 2007, Chen, 2001, Chickering 1987, Swan, 2001). Teacher-student interactions are important not only in motivation of learners but are also important in reinforcing student understanding of the material presented to them and elucidating meanings. Existing literature indicates that teachers' verbal behaviours such as giving praise, soliciting viewpoints, humour, and self-disclosure and nonverbal actions such as physical proximity, touch, eye contact, facial expressions and gestures all can lessen the psychological distance between teachers and their students, thereby leading to increased learning (Swan, 2001). The Teacher is particularly valuable in responding to the learner's application of new knowledge. More opportunities perhaps need to be provided for students to interact more with the teachers as a measure of enhancing the quality of DE courses.

All the items measuring SPQP were further categorized on a Likert type of interval scale ranging from low (10- 20 points) to High $(41-50)$. And therefore in total, the maximum scores a respondent could attain in all 10 items measuring SPQP was $5 \times 10=50$ while the minimum score a respondent could obtain in all the items was $1 \times 10=10$. Subsequently, the following cumulative scoring system was used to classify the students as perceiving pedagogical quality of the DE as either being of low quality, fairly good quality, good quality or high quality. This is summarized below:

$10-20=$ low quality

21- 30 = Fairly good quality

$31-40=$ good quality

$41-50=$ high quality

Results of the analysis indicated that $93.5 \%$ of the students perceived the quality of pedagogy in the DE course as being of a fairly good quality while only $4.9 \%$ of the students perceived the pedagogical quality of DE as being of low quality. This generally implies that the students regard the pedagogical aspects of this course as being fairly good quality.

Spearman's Rank order correlation (rho) coefficients was calculated to see if there was any statistical significance in the relationship between SPQP and SPS. Spearman's rho coefficient was used instead of the Pearson coefficient because most variables were of ordinal nature. Results indicated that there was a weak positive correlation between SPQS and SPS $\left(r_{s}(8)=.019, p=.770\right)$. This implies that SPQP does have an influence on perceived students' satisfaction with the course (SPS).

\subsection{Perception on Learner Support Quality (SPQL)}

Another objective of this study was to analyze students' perception of the quality of Learner support (SPQL) in the DE course and its influence on students' perceived satisfaction (SPS) with the DE course. Leaner support was identified as one of the domains that define the quality of a distance learning program. This domain has also been used for defining quality in DE in other studies (Jung 2011). In this analysis, Leaner support was operationally defined as services availed 
to the learners such as technical, financial, psychological, social, and administrative support, flexible payment among other services that support learners to be comfortable during the learning period. This domain was defined by 10 key related variables and measured though closed-ended Likert five point question items (ranging from 1 (strongly disagree) to 5 (strongly agree). Initially the items measuring this variable were 12 . However, after performing a Reliability testing for internal consistency of the items, two items that scored below the threshold of $\alpha=0.7$ were found not suitable and therefore were eliminated from the final scale that was adopted.

The 10 measures of perception of the quality of Learner support (SPQL) are summarized in table 4 below which also summarizes the standard deviation and mean distributions.

Table 4. Standard deviation and mean distributions of SPQL

\begin{tabular}{|c|c|c|c|}
\hline Variable name & Measurement item & Mean & Standard Deviation \\
\hline VL1 & There is effective learner support & 2.7632 , & 0.78997 \\
\hline VL2 & There is adequate distance learning skills training for all students & 2.5388 & 1.56404 \\
\hline VL3 & There is adequate psychological support for students-such as counseling services & 2.2327 & 0.58583 \\
\hline VL4 & Learner welfare is well taken care of eg financial support, health services & 2.1429 & 0.90536 \\
\hline VL5 & Administrative support in this course is effective & 2.3673 & 0.78651 \\
\hline VL6 & The course is cost effective & 2.3388 & 1.03004 \\
\hline VL7 & There are flexible payment methods for students & 2.3265 & 0.85382 \\
\hline VL8 & We have informal meetings with teachers & 2.33184 & 0.65652 \\
\hline VL9 & We have access to physical library resources & 2.3044 & 0.65172 \\
\hline VL10 & There is access to online library resources & 2.3023 & 0.65176 \\
\hline
\end{tabular}

Most of the items measuring SPQL were scored poorly with mean scores ranging between $\mathrm{ME}=2.1429, \mathrm{SD}=0.90536$ and $\mathrm{ME}=2.7632, \mathrm{SD}=0.78997$. Although majority of the students considered the learner support system to be effective $(\mathrm{ME}=2.7632, \mathrm{SD}=0.78997)$, the other measures of SPQL were scored below the average mean score Psychological support $(\mathrm{ME}=2.2327, \mathrm{SD}=0.58583)$, learner welfare $(\mathrm{ME}=2.1429, \mathrm{SD}=0.90536)$, administrative support $(\mathrm{ME}=2.3673, \mathrm{SD}=0.78651$ ) flexibility in fees payment $(\mathrm{ME}=2.3265, \mathrm{SD}=0.85382)$ course cost $(\mathrm{ME}=2.3388$, $\mathrm{SD}=1.03004$ ). This implies that majority of the students perceive the quality of learner support to be of low quality and this is likely to affect their satisfaction with the course.

Subsequently, the following cumulative scoring system was used to classify the students as perceiving Learner support services as the DE as either being of low quality, fairly good quality, good quality or high quality. This is summarised below:

$10-20=$ low quality

21- 30 = Fairly good quality

$31-40=$ good quality

$41-50=$ high quality

Results of the analysis indicated that $75.8 \%$ of the students perceived the quality of learner support services as being of fairly good quality while only $22.29 \%$ of the students perceived the same to be of a low quality.

Spearman's rho correlation coefficients was run to see if there was any statistical significance in the relationship between SPQL and SPS. Spearman's rho coefficient was used instead of the Pearson coefficient because most variables were of ordinal nature. Results indicated that there was a weak positive correlation between SPQS and SPS $\left(r_{s}(8)=.031\right.$, $p=.635$ ) and which was not significant. This implies that SPQL does not have a strong influence on perceived students' satisfaction with the course (SPS).

\subsection{Perception on the Quality of Faculty (SPQF)}

Another objective of this study was to analyze students' perception of the quality of faculty (SPQF) and support generally given to the teaching staff its influence on students' perceived satisfaction (SPS) with the DE course. The quality of faculty dimension was operationally defined as the level of training of faculty. This domain was defined by three key related variables which students were assumed to have some idea of. These were measured though closed-ended Likert five point question items (ranging from 1 (strongly disagree) to 5 (strongly agree). The 3 measures for the Faculty domain are summarized in table 5. 
Table 5. Standard deviation and mean distributions of SPQF

\begin{tabular}{llll}
\hline Variable Name & Measurement item & Mean & Standard Deviation \\
\hline VF1 & Teachers in this course are well trained and highly qualified & 3.0694 & 0.60673 \\
VF2 & Teachers in this course are quite knowledgeable & 2.5755 & 0.93619 \\
VF3 & There is periodic teacher training & 2.3020 & 0.83874 \\
\hline
\end{tabular}

The three variables measuring SPQF were scored highly with mean scores ranging between ME $=3.0694, \mathrm{SD}=$ 0.60673 and $\mathrm{ME}=2.3020, \mathrm{SD}=0.83874$. The items that Teachers in this course are well trained and highly qualified and Teachers in this course are quite knowledgeable were scored highly in this analysis (ME 3.0694, SD $=0.60673$ and ME 2.5755, SD $=.93619$ respectively. Only VF3 (there is periodic teacher training) was scored below the average mean score $(\mathrm{ME}=2.3020, \mathrm{SD}=0.83874)$

All the items measuring SPQF were further categorized on a Likert type of interval scale ranging from low (10- 20 points) to High $(41-50)$. And therefore in total, the maximum scores a respondent could attain in all 3 items measuring $\mathrm{SPQF}$ was $5 \times 3=15$ while the minimum score a respondent could obtain in all the items was $1 \times 3=03$

Subsequently, the following cumulative scoring system was used to classify the students as perceiving Faculty quality as either of low quality, fairly good quality, good quality or high quality. This is summarized below:

$0-3=$ low quality

4- 7 = Fairly good quality

8- 11 = good quality

$12-15=$ high quality

Results of the analysis indicated that $71 \%$ of the students perceived the quality of faculty to be of as being of a good quality while only (1) $0.4 \%$ of the faculty to be of low quality. $27.4 \%$ perceived the faculty quality to fairly good quality students perceived the same to be of a low quality.

Spearman's rho correlation coefficients was run to see if there was any statistical significance in the relationship between SPQF and SPS. Results indicated that there was a weak positive correlation between SPQS and SPS $\left(r_{s}(8)\right.$ $=.035, p=.590)$ and which was not significant. This implies that SPQF does not have a strong influence on perceived students' satisfaction with the course (SPS).

\subsection{Perception on the Quality of Infrastructure Dimension (SPQI)}

It was important in this study to analyze students' perception on the quality of infrastructure and its influence on students perceived satisfaction (SPS) with the DE course. The infrastructure dimension refers physical infrastructure, technological infrastructure such as availability if computer labs internet access, library and physical spaces. This domain was defined by 6 key related variables and measured though closed-ended Likert five point question items (ranging from 1 (strongly disagree) to 5 (strongly agree). The 6 measures for the infrastructural domain are summarized in table 6 .

Table 6. Standard deviation and mean distributions of SPQI

\begin{tabular}{|c|c|c|c|}
\hline $\begin{array}{l}\text { Variable } \\
\text { name }\end{array}$ & Measurement Item & Mean & $\begin{array}{l}\text { Standard } \\
\text { Deviation }\end{array}$ \\
\hline VF1 & The physical infrastructure in the university is of high quality & 2.8041 & 0.42752 \\
\hline VF2 & Physical classrooms such as learning hall are of high quality & 2.3551 & 0.73022 \\
\hline VF3 & Media production systems are of high quality & 2.4939 & 1.00662 \\
\hline VF4 & Print media used in this course is effective & 2.4367 & 0.7061 \\
\hline VF5 & Other electronic used in this course such as computers, CD ROMs, radio is of high quality & 2.7061 & 0.85133 \\
\hline VF6 & $\begin{array}{l}\text { The technological infrastructure of the university such as availability of computer labs, } \\
\text { internet access is of high quality }\end{array}$ & 2.2082 & 0.79544 \\
\hline
\end{tabular}

The 6 items measuring SPQI were scored poorly with mean scores ranging between ME =, SD $2.8041 \mathrm{SD}=0.42752$ and $\mathrm{ME}=2.2082, \mathrm{SD}=0.79544$. Many of the items measuring this variable were scored below the mean average. For example the items such as the technological infrastructure of the university such as availability of computer labs, internet access is of high quality and Physical classrooms such as learning hall are of high quality were scored (ME $=2.2082, \mathrm{SD}=0.79544 \mathrm{ME}=2.3551, \mathrm{SD}=0.73022$ respectively $)$ were scored below the mean average score of 2.5000 . Only two items (V5 and V6) in this category were scored highly (V5, ME $=2.7061 \mathrm{SD}=0.85133$ and V6, ME $=, \mathrm{SD}$ 2.8041 SD =0.42752). See table 6 . 
All the items measuring SPQI were further categorized on a Likert type of interval scale ranging from low (1- 10 ) to High $(21-30)$. And therefore in total, the maximum scores a respondent could attain in all 6 items measuring SPQI was $5 \times 6=30$ while the minimum score a respondent could obtain in all the items was $1 \times 6=6$

Subsequently, the following cumulative scoring system was used to classify the students as perceiving Faculty quality as either of low quality, fairly good quality, good quality or high quality. This is summarised below:

$1-10=$ poor quality

$11-20=$ Fairly quality

$21-30=$ Good quality

Results of the analysis indicated that $79 \%$ of the students perceived the infrastructural quality to be fair, $13.3 \%$ considered this to be poor and only $6 \%$ of the students perceived the infrastructural facilities to be of high quality. This result may be explained by the fact that the respondents are distance learners and often the university tends to hire teaching and learning facilities especially during residential sessions from other institutions. Rarely have the students used for example the university's' physical space because most of the face to face tutorials are conducted in hired facilities such as nearby high schools whose facilities are usually not of a high quality.

A Spearman's rho correlation coefficients run to see if there was any statistical significance in the relationship between SPQI and SPS indicated that there was a positive correlation between SPQI and SPS $\left(r_{s}(8)=0.156, p=0.05\right)$ and which was significant at 0.05 . This implies that SPQI does have a strong influence on perceived students' satisfaction with the course (SPS).

\subsection{Perception on the Institutional Credibility (SPQC)}

Students perceived quality of a DE course is also seen through students' perception of the credibility of the institution (SPQC) which is often seen in terms of accreditation status, strong institutional leadership and adherence to Quality assurance standards and guidelines. It was therefore important in this study to analyze students' perceived institutional creditability and its influence on students perceived satisfaction (SPS) with the DE course. The institutional credibility dimension was defined by 4 key related variables and measured though closed-ended Likert five point question items (ranging from 1 (strongly disagree) to 5 (strongly agree). The 4 measures for the institutional domain are summarized in table 7.

Table 7. Standard deviation and mean distributions of SPQC

\begin{tabular}{llll}
\hline Variable name & \multicolumn{1}{c}{ Measurement item } & ME & SD \\
\hline VC1 & Courses offered is accredited and of high quality & 2.9633 & 0.74292 \\
VC2 & There is clear institutional quality assurance for our course & 3.1388 & 0.55146 \\
VC3 & The university of Nairobi is a very credible institution of learning & 2.7510 & 0.87734 \\
VC4 & The university leadership is strong and sensitive to our needs & 2.7184 & 1.22067 \\
\hline
\end{tabular}

The 4 variables measuring SPQC were scored highly with mean scores ranging between $\mathrm{ME}=3.1388, \mathrm{SD}=0.55146$ and $\mathrm{ME}=2.7184, \mathrm{SD}=1.22067$. The items that there is clear institutional quality assurance for our course and Courses offered are accredited and of high quality were scored quite highly in this analysis $(\mathrm{ME}=3.1388, \mathrm{SD}=0.55146$ and $\mathrm{ME}=2.9633, \mathrm{SD}=0.74292$ respectively). None of the items measuring SPQC were scored below the average mean score of 2.5000. See table 7 .

All the items measuring SPQC were further categorized on a Likert type of interval scale ranging from low (1- 5) to High $(16-20)$. And therefore in total, the maximum scores a respondent could attain in all 4 items measuring SPQC was $5 \times 4=20$ while the minimum score a respondent could obtain in all the items was $1 \times 4=4$

Subsequently, the following cumulative scoring system was used to classify the students as perceiving Faculty quality as either of low quality, fairly good quality, good quality or high quality. This is summarised below:

$1-5=$ not credible

6- 10 = Fairly credible

11- 15 = highly credible

$16-20=$ extremely credible

Results of the analysis indicated that $70.1 \%$ of the students perceived the institution to be highly credible. Only (28.2\%) of the students perceived the institution as fairly credible.

A Spearman's rho correlation coefficients run to see if there was any statistical significance in the relationship between 
SPQC and SPS indicated that there was a strong positive correlation between SPQC and SPS $\left(r_{s}(8)=.7375, p=.590\right)$. This was significant at 0.01 . This implies that SPQC does have a strong influence on perceived students' satisfaction with the course (SPS).

\subsection{Perception on the Quality of Evaluation (SPQE)}

Lastly, the study analyzed students perceived quality of institutional evaluation mechanisms put in place and how this influences students' perceived satisfaction (SPS) with the DE course. The evaluation and assessment dimension was used in this study to refer to activities and policies concerned with students' learning assessment and feedback as well as various stakeholders' evaluations. The dimension was defined by 5 key related variables and measured though closed-ended Likert five point question items (ranging from 1 (strongly disagree) to 5 (strongly agree). The 5 measures for the Institutional evaluation measures are summarized in table 8.

Table 8. Standard deviation and mean distributions of SPQE

\begin{tabular}{llll}
\hline Variable name & Measurement item & ME & SD \\
\hline VE1 & Course evaluation and procedures are of high quality & 2.8490 & 0.83894 \\
VE2 & There is periodic teacher assessment & 2.4490 & 0.92464 \\
VE3 & There is periodic student assessment & 2.3020 & 0.83894 \\
VE4 & There is timely feedback to students assignments and questions & 2.4939 & 1.25326 \\
VE5 & The university gets feedback from students & 2.7143 & 0.95814 \\
\hline
\end{tabular}

The 5 items measuring SPQE were scored fairly well with mean scores ranging between $\mathrm{ME}=2.8490, \mathrm{SD}=0.80320$ and $\mathrm{ME}=2.3020, \mathrm{SD}=0.83894$. The items that Course evaluation and procedures are of high quality and the university gets feedback from students were scored quite highly in this analysis $(\mathrm{ME}=2.8490, \mathrm{SD}=0.80320$, and $\mathrm{ME}=2.7143, \mathrm{SD}$ $=0.95814$ respectively). However, three of the items measuring SPQE were scored below the average mean score of 2.5000 with the item there is periodic teacher assessment scoring the lowest (and ME $=2.3020, \mathrm{SD}=0.83894$ ). See table 8 .

All the items measuring SPQE were further categorized on a Likert type of interval scale ranging from low (5 - 10 ) to High $(21-25)$. And therefore in total, the maximum scores a respondent could attain in all 5 items measuring SPQE was $5 \times 5=25$ while the minimum score a respondent could obtain in all the items was $1 \times 5=5$

Subsequently, the following cumulative scoring system was used to classify the students as perceiving quality of evaluation as either of low quality, fairly good quality, good quality or high quality. This is summarised below:

$5-10=$ low quality

$11-15=$ Fairly good

$16-20=\operatorname{good}$ quality

$21-25=$ high quality

Results of the analysis indicated that $66.91 \%$ of the students perceived the quality of evaluation to be of fairly good quality while $17.7 \%$ of the students perceived the institution evaluation as of low quality.

A Spearman's rho correlation coefficients run to see if there was any statistical significance in the relationship between SPQE and SPS indicated that there was a strong positive correlation between SPQE and SPS $\left(r_{s}(8)=.826, p=.0 .01\right)$. This implies that SPQE does have a strong influence on perceived students' satisfaction with the course (SPS).

\section{Discussions, Conclusions and Recommendations}

The inherent nature of distance education places additional responsibilities on students and therefore quality should and must be seen in the students' lenses. Students in this survey were not only able to indicate their perception of quality from different perspectives but it was also clear that these perceptions are related to their perceived satisfaction with the DE course. This points to the conclusion that institutions must pay attention to factors such as quality of pedagogy, learner support, technological and even physical infrastructure structure as a measure of meeting students' Quality expectations. This study for instance indicated that the students perceived the quality of learner support services as being weak, a factor that is likely to affect their satisfaction with the course. Dissatisfaction with a learning experience is of course one factor that has been associated with leaner attrition (Ludwig-Hardman, 2003, Thompson, 1989).

Results of the study clearly indicated that the theory predictor variables (SPQP, SPQL, SPQI, SPQC, SPQF and SPQE) were all positively correlated with perceived students' satisfaction with the DE course. Learners particularly seemed to value fair and clear learning assessment guidelines and periodic students' evaluation of teaching and learning. This 
finding is s also supported by previous studies, which have reported a significant association between evaluation and assessment in assuring the quality of e-learning (Simpson, C. and Gibbs, G. 2004, Frydenberg, 2002, Tait, 1993, Alavi, M. 1994)

DE teachers need to be well trained to appreciate their roles in facilitating learning in DE courses. One of the challenges faced by DE programs offered in a Dual systems (Where both conventional and DE approaches are used in delivering courses) is the use of teachers who are accustomed to Conventional face to face tutoring. Often in such circumstances, teachers are not given any additional training to help them manage distance education programs. This often results to the faculty using the same approaches used in face- face tutoring with total disregard of the special needs and demands of the DE learner and DE approaches. There is need therefore to make deliberate efforts to train and orientate these faculty and equip them with the necessary capacity to manage DE learners and programs.

Results of this study also indicated that learners rated the course content to be of fairly good quality. This is an area that too needs improvement as content interaction is usually valued highly by the distance learners (Thurmond, V. A. 2003, Frey, B. A., Alman, S. W., Barron, D., \& Steffens, A. 2004). The quality of content may be affected by many factors such as adequate availability of the content, continuous contact with the content, clarity of course design, and other factors such as adequate time for the learners to go through the content. This calls for deliberate effort to be made in ensuring effective course design and availability of adequate content in the form of study learning resources and effective connectivity where the courses are offered online. There is also need to train students in study skills and management of time for them to reap maximum benefits of course content.

\section{Limitations of the Study and Areas for Further Research}

One major caveat of this study is that it was based on data gathered from a limited sample of students following a Bachelors of Education Arts program at the university of Nairobi. Perhaps a larger diversified sample with different subject areas could enrich the interpretations of the theory constructs analyzed in the study. Secondly, only quantitative analysis was used and therefore more detailed in-depth explanation of the theory variables were not exhaustively explained. This therefore limits the generalizability of the results of this study beyond the research setting.

\section{Acknowledgement}

I would like to deeply acknowledge respondents to this study who gave very insightful data and without whom this analysis would not have been realized. I particularly want to appreciate the Bachelors of Education Arts program students year 2013 at the university of Nairobi for their willingness to participate in the study.

\section{References}

Alavi, M. (1994). Computer-mediated collaborative learning: an empirical evaluation. MIS Quarterly, 18, $159-174$. http://dx.doi.org/10.2307/249763

Belawati, T., \& Zuhairi, A. (2007). The Practice of a Quality Assurance System in Open and Distance Learning: A case study at Universitas Terbuka Indonesia (The Indonesia Open University). International Review of Research in Open and Distance Learning, 8(1), Athabasca University.

Cashion, J., \& Palmieri, P. (2002). The secret is the teacher: The learners' view of online learning. Leabrook, Australia: National Centre for Vocational Education Research. Retrieved from http://www.ncver.edu.au/research/proj/nr0F03a.pdf

Chen, Y. (2001a). Transactional distance in World Wide Web learning environments. Innovations in Education and Teaching International, 38(4), 327-338. http://dx.doi.org/10.1080/14703290110074533

Chen, Y. (2001b). Dimensions of transactional distance in the world wide web learning environment: A factor analysis. British Journal of Educational Technology, 32(4), 459-470. http://dx.doi.org/10.1111/1467-8535.00213

Chickering, A. W., \& Ehrmann, S. C. (1996). October. Implementing the Seven Principles: Technology as Lever. AAHE Bulletin, 49(2), 3-6.

Chickering, A. W., \& Gamson, Z. F. (1987). Seven Principles of good practice in undergraduate education. $A A H E$ Bulletin, 39(7), 3-7.

Cortina. J. M. (1993). What is coefficient alpha? An examination of theory and applications. Journal of Applied Psychology, 78, 98-104. http://dx.doi.org/10.1037/0021-9010.78.1.98

Daugherty \& Barbara. (1998). University Faculty and Student Perceptions of Web-Based Instruction. Journal of Distance education, 13(1), 21-39

Harman, G. (2000). Quality assurance in higher education. Bangkok: Ministry of University Affairs \& UNESCO PROAP. 
Ehlers, U. (2004). Quality in e-learning from a learner's perspective. European Journal of Open and Distance Learning, 1. Retrieved from http://www.eurodl.org/materials/contrib/2004/Online_Master_COPs.htm

Frey, B. A., Alman, S. W., Barron, D., \& Steffens, A. (2004). Student satisfaction with the online MLSI program at the University of Pittsburgh. Journal of Education for Library and Information Science, 45, 82-97. http://dx.doi.org/10.2307/40323896

Frydenberg, J. (2002). Quality standards in e-Learning: A matrix of analysis. International Review of Research in Open and Distance Learning, 3(2). Retrieved from http://www.irrodl.org/index.php/irrodl/article/viewArticle/109/189

Jung, I. S. (2011). The dimensions of e-learning quality: From the learner's perspective. Educational Technology Research and Development, 59(4), 445-464. http://dx.doi.org/10.1007/s11423-010-9171-4

Jung, I. S., Wong, T. M., Chen L., Baigaltugs, S., \& Belawati, T. (2011). Quality assurance in Asian distance education: Diverse approaches and common culture. International Review of Research in Open and Distance Learning 12(6), 63-83. Retrieved from http://www.irrodl.org/index.php/irrodl/article/view/991/1990

Ludwig-Hardman. (2003). Learner Support Services for Online Students: Scaffolding for success. International Review of Research in Open and Distance Learning, 4(1), Athabasca University

Nugraheni et al. (2014). Students' perception on quality assurance system of distance education at Universitas Terbuka 2014, PAN Asia Networking Distance and Open Resources Access.

Nunnally, J. C. (1978). Psychometric Theory, 2nd ed. New York: McGraw-Hill.

Parker, N. (2004). The quality dilemma in online education In Theory and practice of online learning, Chapter 16. Athabasca, AB: Athabasca University Press, Retrieved January 4, 2014, from http://cde.athabascau.ca/online_book/ch16.ht

Revelle, W. (1979). Hierarchical cluster analysis and the internal structure of tests. Multivariate Behavioral Research, 14, 57-74. http://dx.doi.org/10.1207/s15327906mbr1401_4

Swan, K. (2001). Virtual interaction: Design factors affecting student satisfaction and perceived learning in asynchronous online courses. Distance Education, 22, 306-331. http://dx.doi.org/10.1080/0158791010220208

Simpson, C., \& Gibbs, G. (2004). Improving student progress and retention through support mechanisms. Paper delivered at the 21 .

Tait, A. (ed.). (1993). Quality assurance in open and distance learning: European and international perspectives. Conference Papers Cambridge Open University.

Thurmond, V. A. (2003). Examination of interaction variables as predictors of students' satisfaction and willingness to enroll in future Web-based courses while controlling for student characteristics. Published Dissertation. University of Kansas. Parkland, FL: Dissertation.com. Available online http://www.dissertation.com/library/1121814a.htm

Thompson, G. (1989). The Provision of Student-support Services in Distance Education: Do we know what they need? In R. Sweet (Ed.) Post-secondary distance education in Canada: Policies, practices, and priorities. Athabasca, AB.: Athabasca University.

Tucker, A. (2010). Effective practices in e-learning: An online instructor and learner perspective. In J. Sanchez \& K. Zhang (Eds.), Proceedings of World Conference on E-Learning in Corporate, Government, Healthcare, and Higher Education 2010 (p. 1251). Chesapeake, VA: AACE.

University of Nairobi. (1990). A report to the Vice-Chancellor and Senate on Current Status, Progress and Restructuring of the External Degree programme, Faculty of External Studies: Nairobi.

\section{$(\mathrm{cc}) \mathrm{Br}$}

This work is licensed under a Creative Commons Attribution 3.0 License. 